\title{
A new time-delayed periodic boundary condition for discrete element modelling of railway track under moving wheel loads
}

\author{
Huiqi Li ${ }^{1}$ (D) Glenn McDowell ${ }^{1}$. John de Bono ${ }^{1}$
}

Received: 3 May 2020 / Accepted: 12 April 2021 / Published online: 9 August 2021

(C) The Author(s) 2021

\begin{abstract}
A new time-delayed periodic boundary condition (PBC) has been proposed for discrete element modelling (DEM) of periodic structures subject to moving loads such as railway track based on a box test which is normally used as an element testing model. The new proposed time-delayed PBC is approached by predicting forces acting on ghost particles with the consideration of different loading phases for adjacent sleepers whereas a normal PBC simply gives the ghost particles the same contact forces as the original particles. By comparing the sleeper in a single sleeper test with a fixed boundary, a normal periodic boundary and the newly proposed time-delayed PBC (TDPBC), the new TDPBC was found to produce the closest settlement to that of the middle sleeper in a three-sleeper test which was assumed to be free of boundary effects. It appears that the new TDPBC can eliminate the boundary effect more effectively than either a fixed boundary or a normal periodic cell. Discrete element modelling $\cdot$ Railway mechanics $\cdot$ Cyclic loading $\cdot$ Boundary effect
\end{abstract}

\section{Introduction}

One major challenge for discrete element modelling (DEM) of practical particulate systems is the low computational efficiency as the real field system normally involves millions of particles. Element testing models are the most commonly used method to reduce the number of modelled particles and thus increase the computational efficiency. For example, the railway track system has been investigated by simulating 'box tests' [1-6], cone penetration tests (CPT) and triaxial tests [7-11] to understand the ballast mechanics. However, the artificial boundaries in such simulations can have significant effects on granular movement $[12,13]$. To eliminate the boundary effects, periodic boundary conditions (PBCs) have been recognized as a useful tool [11,12,14-17] for some models. PBCs are normally used when the whole particle system can be represented by repeated and identical representative unit cells along the whole space [18]. The PBC was

Huiqi Li

Huiqi.Li@nottingham.ac.uk

Glenn McDowell

Glenn.McDowell@nottingham.ac.uk

John de Bono

ezzjd@exmail.nottingham.ac.uk

1 Nottingham Centre for Geomechanics, University of Nottingham, Nottingham, UK initially applied to rectangular samples $[10,11]$. Figure 1a illustrates the principle of the rectangular PBC which simply allows the particles located at one of the periodic boundaries to interact with the particles located at the other, opposite periodic boundary, which is achieved by duplicating the particles in the simulation cell itself.. Cui et al.(14) proposed a circumferential PBC adapted to the axisymmetric samples where the periodic domain was represented as a sector model. The principle is similar and illustrated as Fig. 1b: the particles next to one boundary are duplicated symmetrically about the symmetry axis and are imposed against the other boundary.

However, the above PBCs are not appropriate for nonsymmetrical loads, such as the problem of loads travelling along a railway track. In this case, as Fig. 2 illustrates, the sleepers transfer load from the rail to the ballast, and the instantaneous loads transmitted from the sleepers vary based on their distances to the moving wheel. Typically, in both experimental tests and in DEM simulations, this loading regime is implemented by applying out-of-phase sinusoidal loads to the sleepers [19-21], which is demonstrated in $1^{*}$ MERGEFORMAT Fig. 3. Sub-figure (a) shows (as an example) that when the wheel is directly above a sleeper, this sleeper has the maximum load, whilst the adjacent sleepers carry approximately $1 \frac{1}{2}$ load [22-24]. I* MERGEFORMAT Fig. 3b shows the non-uniform applied loads for when the wheel is between sleepers. 


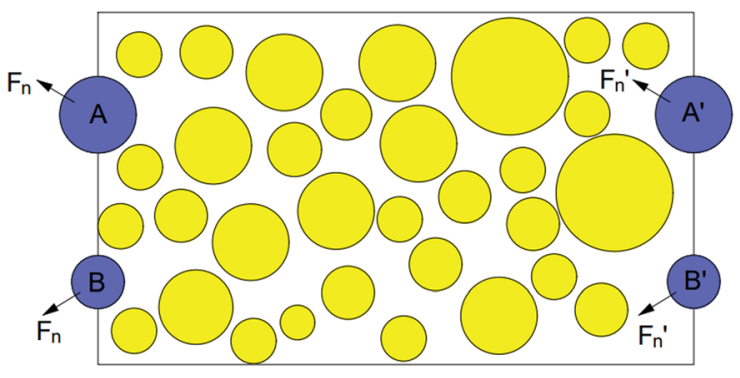

(a)

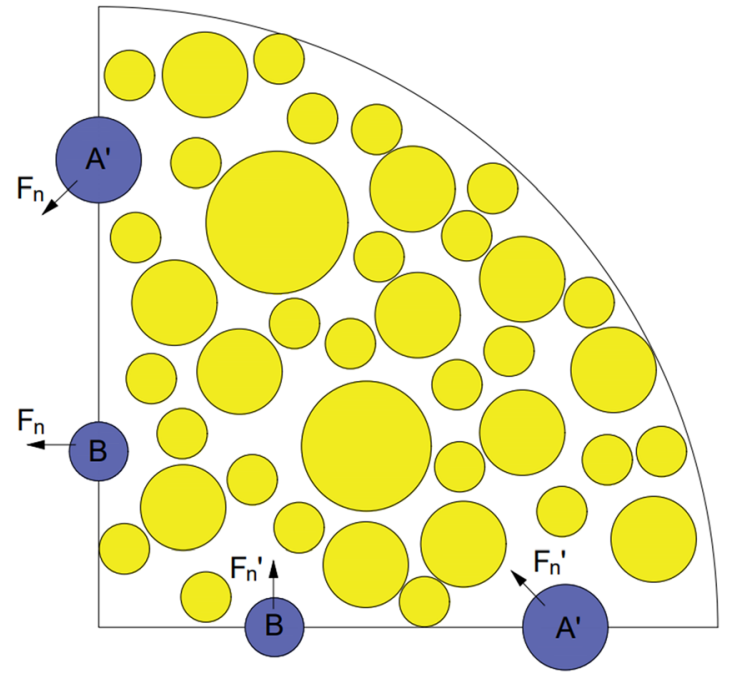

(b)

Fig. 1 Illustration of (a) rectangular periodic boundary and (b) circumferential periodic boundary

Fig. 2 Load distribution of adjacent elements under moving load

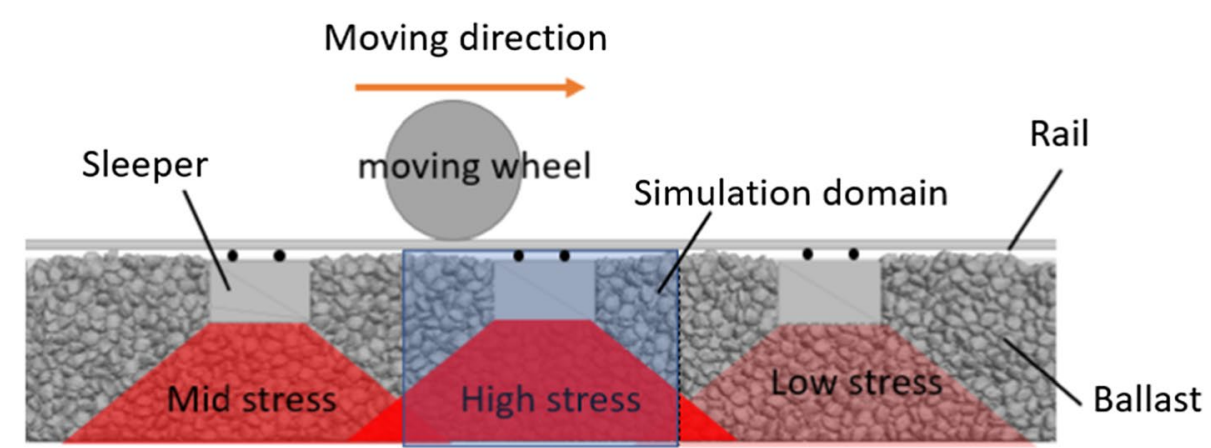

A DEM model including only one sleeper and the surrounding ballast (labelled simulation domain in Fig. 2) was used as the simulation cell in this study and is referred to as a 'box test'. The box test has been widely used to study railway track loading both experimentally and numerically [2, 4, 25-33], due to time/cost efficiency. In this case, the modelled representative element is not completely repeatable, as adjacent sleepers are subjected to different phases of the cyclic moving loads ( ${ }^{*}$ MERGEFORMAT Fig. 3b), and thus the particles located at the boundary (e.g. particle $\mathrm{A}$ in Fig. 1a) and its duplicated particle at the other side (particle A') would be subjected to different stress conditions by sleepers at the different loading phases. Although the dynamics of structures under periodic (cyclic) moving loads have been studied by quite a number of researchers, most of them were employing mathematical methods such as a Fourier-series technique [20, 21, 34], the Floquet theorem [35, 36] and Floquet decomposition [37]. To the authors' knowledge, there is no published DEM study investigating the application of PBC under moving loads. This study aims to propose a novel 'time-delayed' PBC for DEM modelling of a non-symmetrical periodic structure under moving loads.

Two box test configurations were conducted in this study, one with a single sleeper and the other with three sleepers (in which loads can be applied out of phase to the three individual sleepers). The mechanical behaviour of the middle sleeper in the three-sleeper box test was regarded as being sufficiently far from the boundaries for the boundary effect to be negligible; the adjacent sleepers create the necessary conditions for the central sleeper to be subject to the correct loading conditions. The behaviour of this test, specifically that of the central sleeper, is compared to that of the single sleeper box test, using various boundary conditions. Three alternative boundary conditions were used: fixed boundary, normal PBC and the new time-delayed PBC. By comparing the behaviour of the central sleeper in the three-sleeper test to the single sleeper 


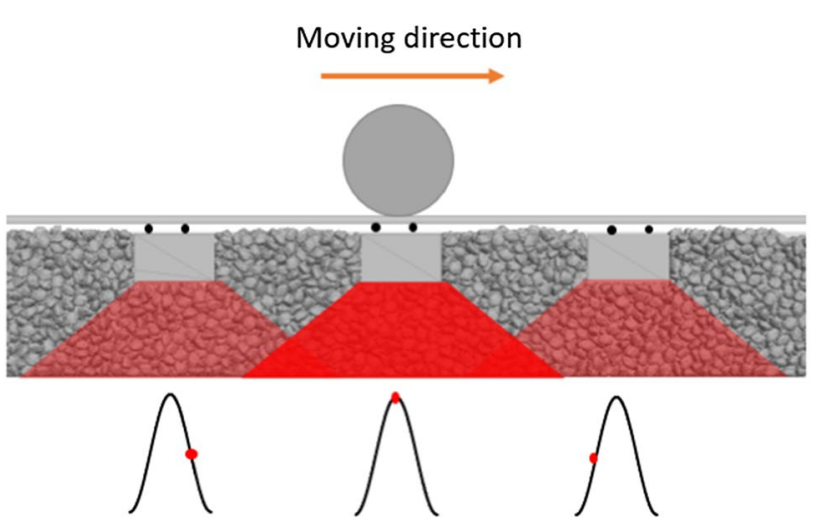

(a)

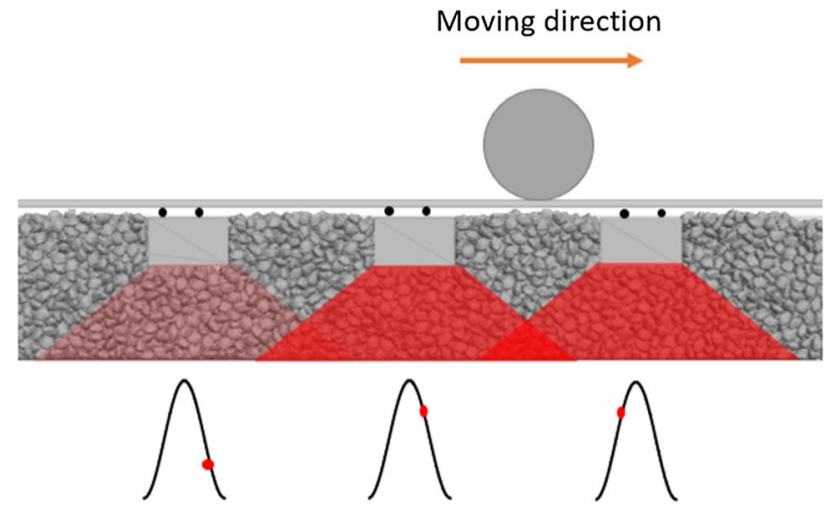

(b)

Fig. 3 Simulation of a moving wheel load (a) Moving wheel directly on a sleeper (b) Moving wheel on the position between sleepers

test with periodic boundaries, this investigation aims to establish whether the new time-delayed periodic cell can capture the dynamic, out-of-phase loading for a greatly reduced number of particles.

\section{Box test conditions}

The box test simulates the ballast-sleeper interaction occurring under the rail seat of a track (Fig. 4). Previous studies $[2,38-40]$ have shown the apparatus used in this study to be a useful method of simulating realistic track loads on railway ballast in order to assess the effects of specific track variables. It simply consists of loading cyclically a section of sleeper which is embedded into ballast confined in a $0.3 \times 0.7 \times 0.45 \mathrm{~m}$ box (Fig. $5 \mathrm{a}$ ). The sleeper section is loaded vertically with a $3 \mathrm{~Hz}$ cyclic load oscillating between 3 and $40 \mathrm{kN}$. In the present numerical approach a three-sleeper case has also been simulated using a box three times as wide (Fig. 5b), similar to the Nottingham Railway Test Facility [19] as shown in Fig. 6. In this case the sleepers are loaded sequentially with 90 degrees phase angle delay along the axis of the propagation of the load which are similar to the conditions for the Railway Test Facility, as shown in I* MERGEFORMAT Fig. 7. To measure the effect of the boundary conditions on the settlement of the sleeper, results of the single sleeper box test are compared with the results obtained with the middle sleeper of the three-sleeper test.

\section{DEM model}

The commercial DEM code PFC3D [41] was used in this study. DEM considers granular materials like ballast as an assembly of objects interacting through a contact law. A Hertz-Mindlin [41] contact law characterised by a Youngs modulus $E$ and a Poisson ratio $v$ has been used to calculate, from the overlap between two objects, normal and shear elastic forces. The ratio between the shear and normal contact force components is limited using a Mohr-Coulomb sliding criterion characterised by a friction coefficient $f$. This is the contact model embedded in
Fig. 4 Simulated track area of box test and the box test apparatus
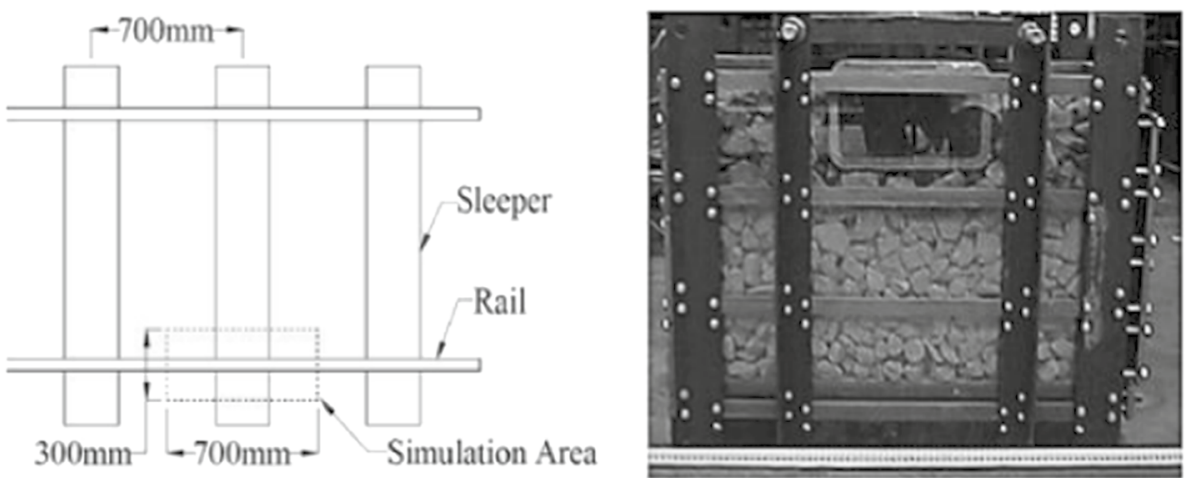


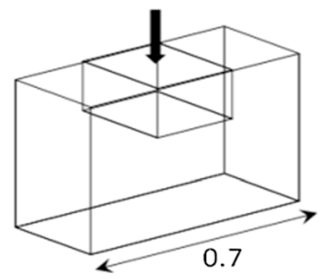

(a)

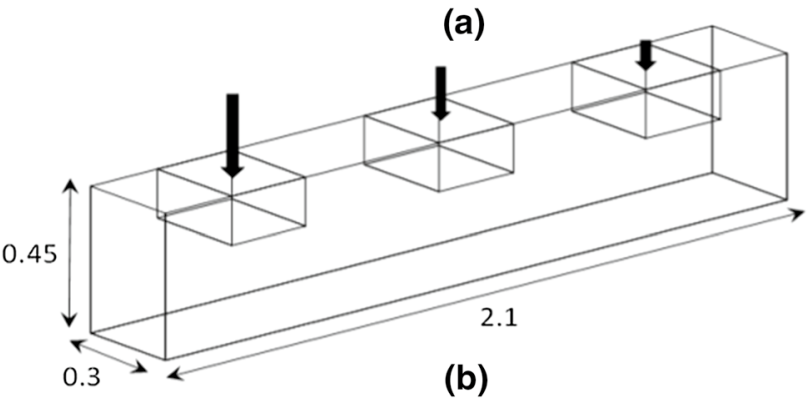

Fig. 5 Box test configuration (a) three-sleeper (b) single sleeper

the DEM code PFC ${ }^{3 \mathrm{D}}$ used in this analysis. The acceleration of each object is deduced from the contact forces acting on it using Newton's second law, and then its velocity and displacement by integration using a timestepping scheme. The displacement of the objects then leads to new overlaps and new contact forces creating a complete DEM calculation cycle. The displacement of the objects is then determined as a function of time (number of timesteps $\mathrm{x}$ time increment). A non-viscous damping force reducing the acceleration of the particles by $70 \%$ is introduced into the model to avoid non-physical oscillation within the assembly of objects and allow further dissipation of energy in addition to friction at contacts [41].

The particles are modelled as 'clumps' with a single, realistic shape as scanned by $\mathrm{Li}$ et al. $[42,43]$ as $\left.\right|^{*}$ MERGEFORMAT Fig. 8 shows. For a given scanned particle surface, PFC3D is able to create a 'clump' of the same shape by using the algorithm of Taghavi [44] (see also Li and McDowell [2]). The clumps used in the simulations have a particle size distribution typical of ballast used by Network Rail UK [45]. The mechanical parameters of the simulated ballast particles were determined in previous studies [2] and are summarized in Table 1. The same contact model operates for the walls.

Figure 9 shows the generated DEM samples for the two test configurations. The top sample was generated with a simple deposition method; details are given in $\mathrm{Li}$ and McDowell [2]. The bottom sample is generated by deleting the two entire outer "boxes" (i.e. outer thirds of the sample) including the boundaries, particles and sleepers of top sample and applying alternative boundary conditions (fixed boundary, normal PBC; new time-delayed PBC) to the left and right hand sides of the sample.

\section{Boundary effect for fixed boundary and normal periodic boundary}

Firstly, fixed boundaries and standard (no time-delay) PBCs were applied to single sleeper tests. The fixed boundary here means rigid walls with the same parameters as listed in Table 1. I* MERGEFORMAT Fig. 10 shows the sample with standard PBCs - which has periodic boundaries on either side. The light grey particles are the standard particles and constitute the bulk of the sample. The red particles are the 'mirrored' or duplicated particles, which will be called 'ghost particles' in this paper. Only the 2 lateral boundaries shown in the figure were used as periodic boundaries, as this is the direction in which traffic loads move along (not into/out of the page).

The standard PBCs were applied according to the following procedure. The position and surfaces of all particles were continuously monitored every timestep. When any particle surface comes in to contact with (touches or overlaps) the lateral boundaries/planes (e.g. Particles A and B in I* MERGEFORMAT Fig. 10), a corresponding particle is created at the opposite side of the box (e.g. Particle A' and B'). This duplicated particle has an identical shape and is created with the same orientation. This ghost particle therefore provides a physical boundary at the opposite side of the box, preventing the internal normal particles from escaping the sample.

The net force acting on the ghost particle has the same magnitude and direction as those acting on the original particle. The ghost particle also has an identical velocity to the original particle. For position relocation, it was treated as a shift along the periodic direction. For the sample used in this study, with a coordination system shown in ${ }^{*}$ MERGEFORMAT Fig. 10, the coordinates of ghost particle $\left(\mathrm{x}_{\mathrm{g}}, \mathrm{y}_{\mathrm{g}}, \mathrm{z}_{\mathrm{g}}\right)$ for the original particle $\left(\mathrm{x}_{0}, \mathrm{y}_{\mathrm{o}}, \mathrm{z}_{\mathrm{o}}\right)$ could be represented as:

$x_{g}=\left\{\begin{array}{l}\mathrm{x}_{o}+L, \mathrm{x}_{o}<0 \\ \mathrm{x}_{o}-L, \mathrm{x}_{o} \geq 0\end{array} ; y_{g}=y_{o} ; z_{g}=z_{o}\right.$

where $L$ is the length of the sample in the periodic direction.

I* MERGEFORMAT Fig. 11 shows the deflections of the sleepers as a function of time for the cases of the central sleeper in three-sleeper test, the single sleeper box test with the fixed boundary and also with normal PBCs. The central sleeper in the three-sleeper test, which is considered as being without boundary effects in this study, clearly presents a much larger settlement than the single sleeper box test with the fixed boundaries. That is to say, the application of simple fixed boundaries does cause a boundary effect-clearly reducing the sleeper settlement. The settlement curve for standard PBC lies in the middle, which means although this boundary effect has been attenuated by changing the fixed boundary to a normal PBC, the PBC is not able to eliminate the boundary effect. 
Fig. 6 Nottingham Railway Test Facility (a) Cross0section of the facility (b) Assembled loading arrangement (19)

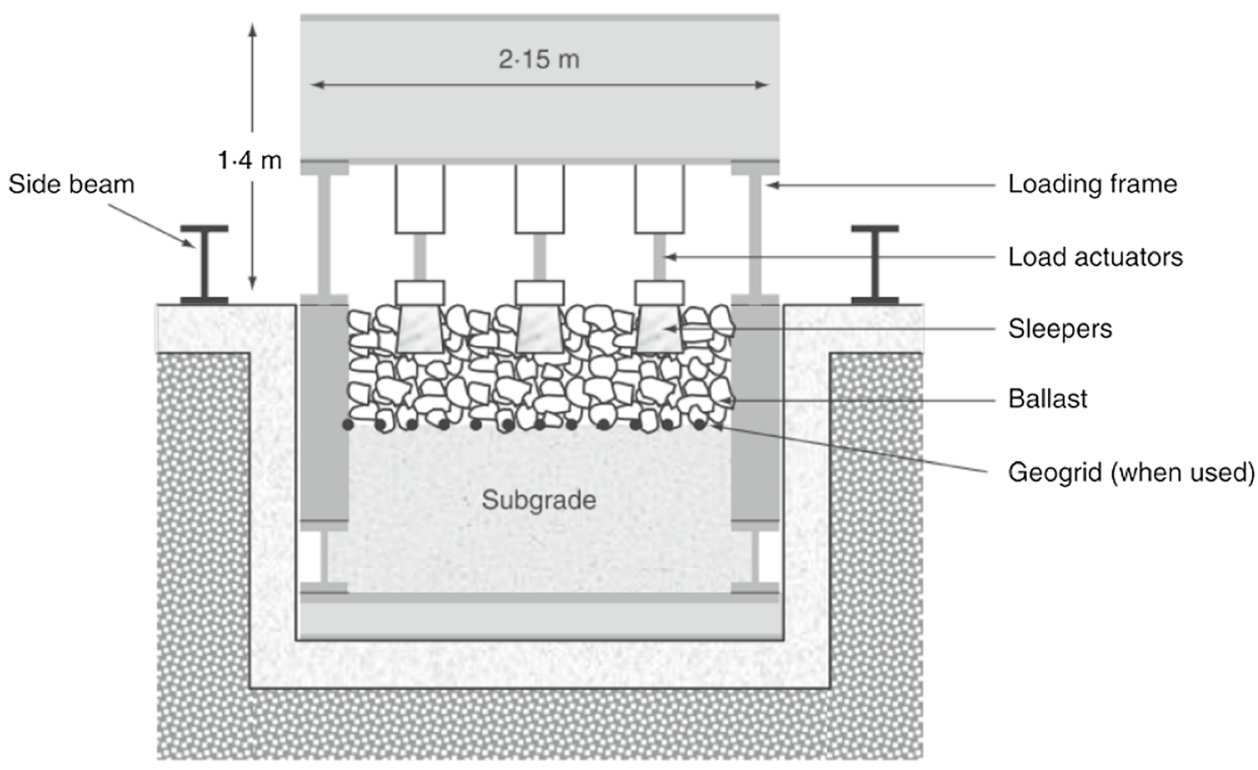

(a)

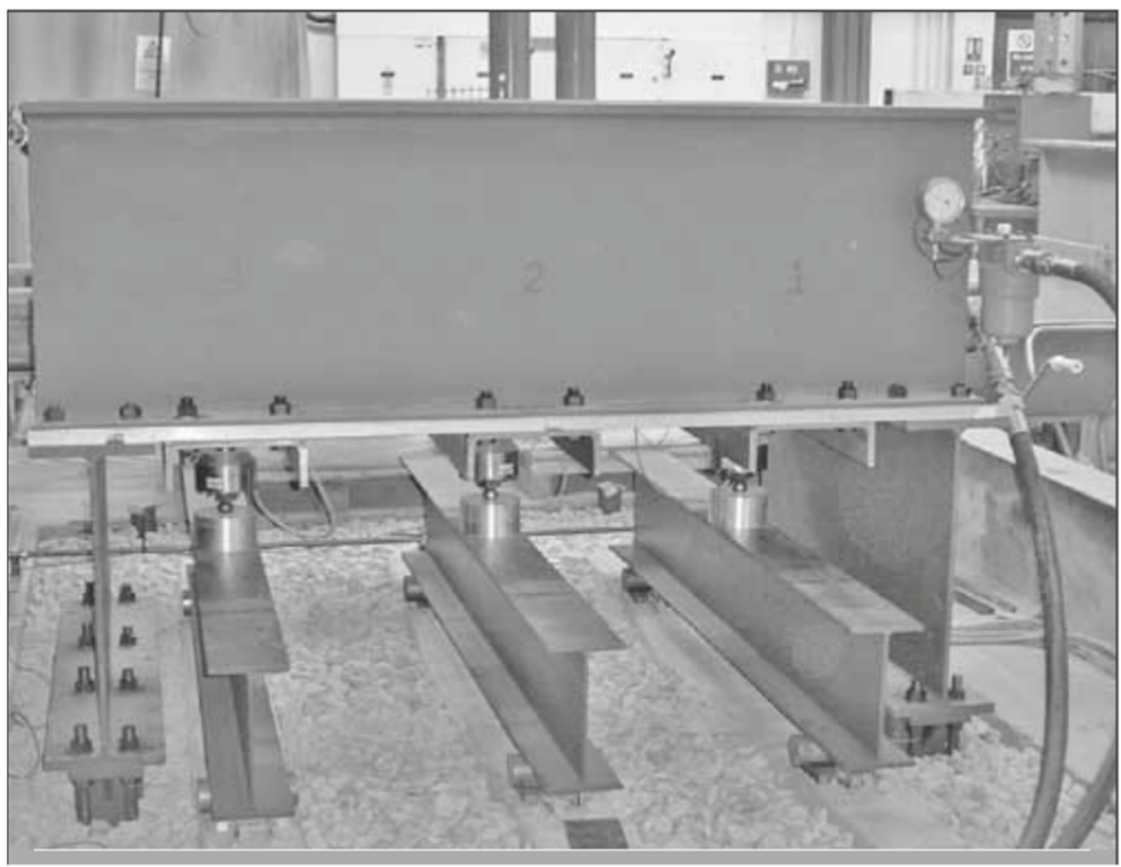

(b)

\section{The time-delayed periodic boundary (TDPBC)}

The reason why the normal periodic boundary cannot eliminate the boundary effect is that it assumes the particles moving outside the boundary and the corresponding reintroduced particles have the same mechanical behaviour (velocity and net contact force), which means it assumes the three sleepers in this study are always being loaded in phase, as $\downarrow^{*}$
MERGEFORMAT Fig. 12a illustrates. However, with a moving load, the actual loads on the three sleepers are out of phase as $\backslash^{*}$ MERGEFORMAT Fig. 12b shows. Therefore, to get a more compatible PBC, the mechanical condition applied on the ghost particles should consider the change of loading phase for adjacent periodic elements.

The investigations started from the analysis of the contact force chains on the single sleeper test with fixed

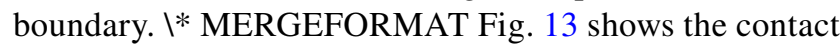
force chains at four different loading phases of the $10^{\text {th }}$ 


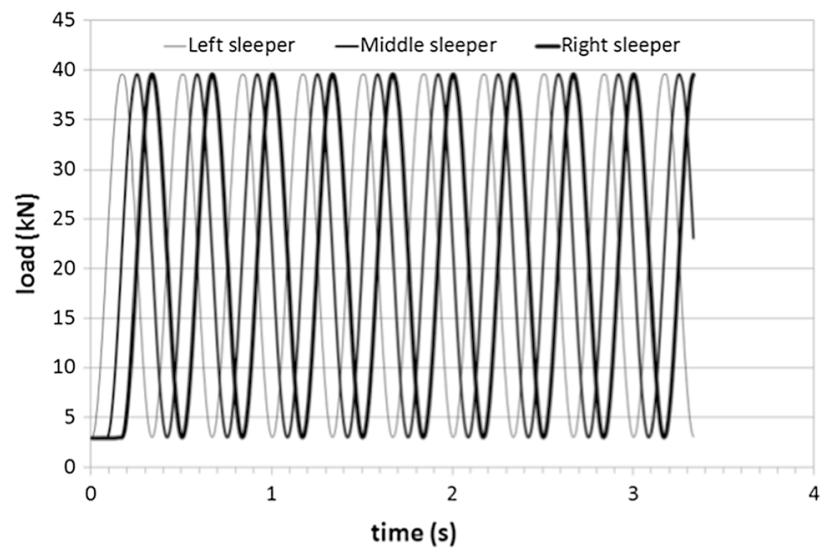

Fig. 7 Cyclic loading acting on the three sleepers

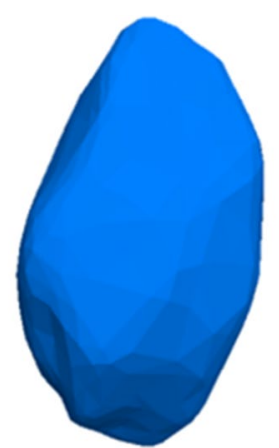

\section{Actual particle shape}

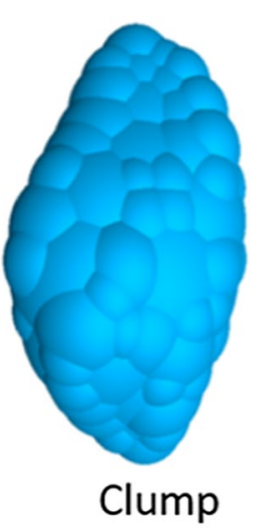

Fig. 8 Actual particle shape and clump used in DEM model

Table 1 Input parameters of clump particle and boundary

\begin{tabular}{ll}
\hline Properties of clump with real shape & \\
Friction & 0.5 \\
Poisson's ratio & 0.25 \\
Shear modulus & $28 \mathrm{GPa}$ \\
No. of spheres forming clump & 41 \\
c_dis & $150^{\circ}$ \\
c_ratio & 0.4 \\
Density & $2,960 \mathrm{~kg} / \mathrm{m}^{3}$ \\
Damping coefficient & $0.7(\mathrm{default})$ \\
Properties of boundary & \\
Poisson's ratio & 0.25 \\
Shear modulus & $28 \mathrm{GPa}$ \\
Friction & 0.5 \\
\hline
\end{tabular}

loading cycle at the same scale (where thickness represents force magnitude). It can be seen for all the four time points in the cycle, the shape of contact force chains are quite similar; the major difference is the magnitude of contact force which changes with the sleeper load: the contact forces increase with increasing sleeper loads and should be proportional to and in phase with the sleeper load. This fact was then used to explore the possibility of predicting the contact forces based on the known sleeper loads.

I* MERGEFORMAT Fig. 14 plots both the average magnitude of the contact forces for the particles in contact with both the left and right boundaries combined and the sleeper load as a function of number of loading cycles. I* MERGEFORMAT Fig. 14 clearly shows that the average magnitude of the boundary contact forces is approximately proportional to and in phase with the sleeper loads.

If the average magnitude of contact forces $\mathrm{F}_{\text {Ave }}$ on each boundary is assumed to be a sinusoidal function of loading time during any single loading cycle as observed from $\backslash^{*}$ MERGEFORMAT Fig. 14, the average magnitude of contact forces for both boundaries combined $\mathrm{F}_{\text {Ave_current }}$ at any time point would be expressed as:

$F_{\text {Ave_current }}=\frac{F_{\text {Ave_max }_{-}}+F_{\text {Ave_min }_{-}}}{2}+\frac{F_{\text {Ave_max }_{-}}-F_{\text {Ave_min }_{-}}}{2} * \sin \Phi$

where $\Phi$ is the phase angle for this time point, $\mathrm{F}_{\text {Ave_max }}$ and $\mathrm{F}_{\text {Ave_min }}$ are the average magnitudes of the boundary contact forces at the maximum and minimum sleeper loads during the sleeper loading cycle.

In DEM simulations, for the value of current sleeper load during the current cycle, $\Phi$ is a known value, and the $\mathrm{F}_{\text {Ave_current }}$ is easily calculated directly from the DEM model. $F_{\text {Ave_min }}$ is also a known value as it is the first data point for each sinusoidal cycle, so $F_{\text {Ave max }}$ is unknown for the first half of the loading cycle where the sleeper load hasn't reached the maximum point. In this case, $F_{\text {Ave_max }}$ could be estimated by solving Eq. 2:

$F_{\text {Ave_max }}=\left(2 * F_{\text {Ave_current }}-(1-\sin \Phi) * F_{\text {Ave_min }}\right) /(1+\sin \Phi)$

In fact, to allow for the fact that the average boundary contact force and maximum average contact force will not be precisely proportional to current and maximum sleeper loads respectively, the current value of $\mathrm{F}_{\text {Ave_current }}$ for both boundaries combined is updated each timestep and then substituted into Eq. (3) to get the corresponding $\mathrm{F}_{\text {Ave_max }}$. Hence, for the known minimum Average contact force for the current cycle and phase angle together with the current average, the average magnitude of boundary contact force as a sinusoidal function of time for the whole loading cycle can be predicted, following Eq. (2) for different phase angles.

The traffic loading is travelling from left to right. So given the calculated boundary contact forces for the fixed wall case above, for the case of a periodic cell which accounts for the travelling load and the out of phase loading of what would 
Fig. 9 DEM samples of box test (a) Three-sleeper (b) Single sleeper

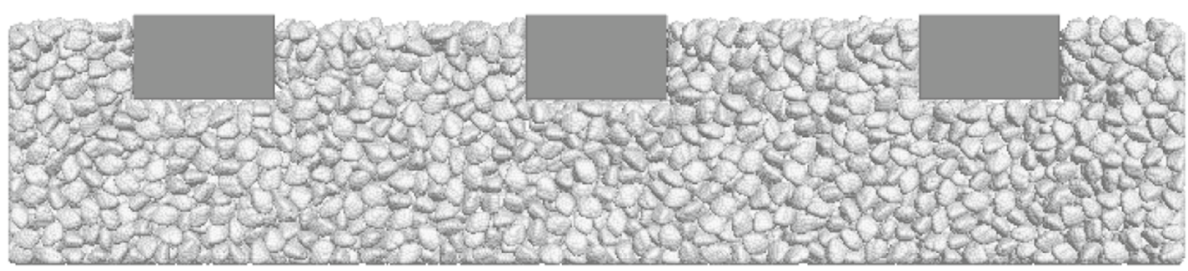

(a)

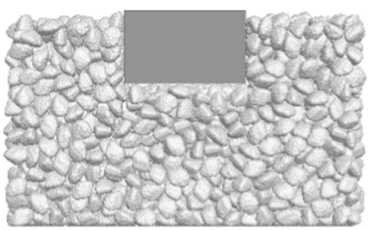

(b)

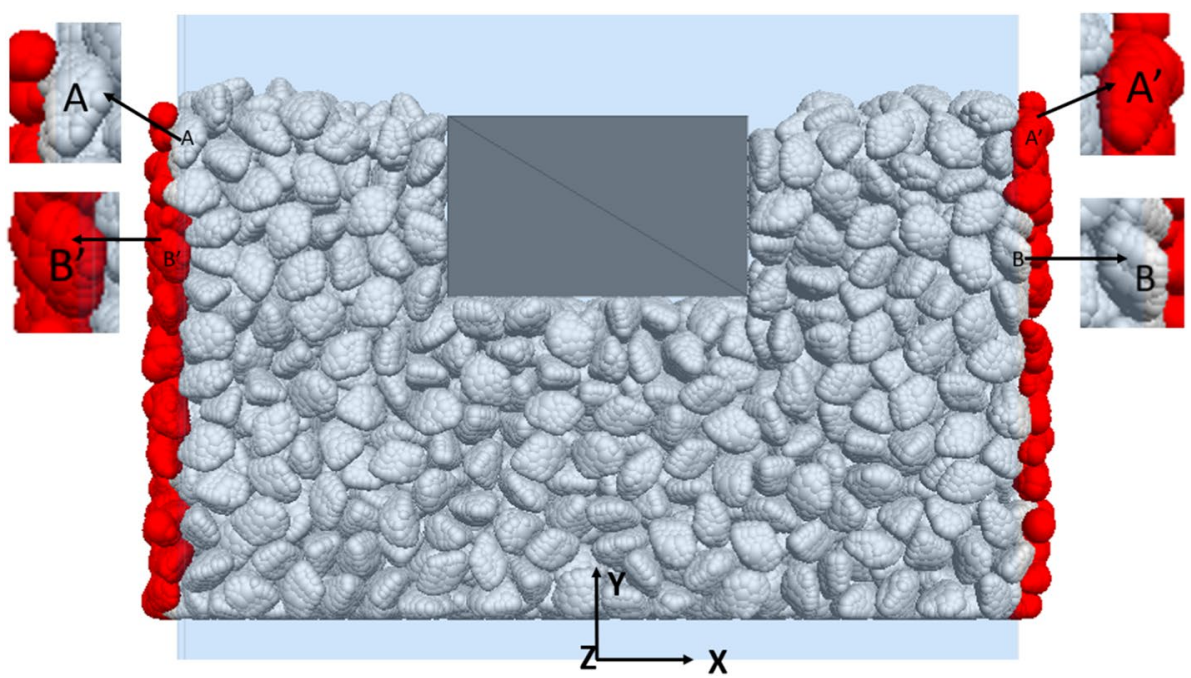

Fig. 10 Sample of single sleeper box test with normal rectangular PBC

Fig. 11 The boundary effects of fixed boundary and normal PBC

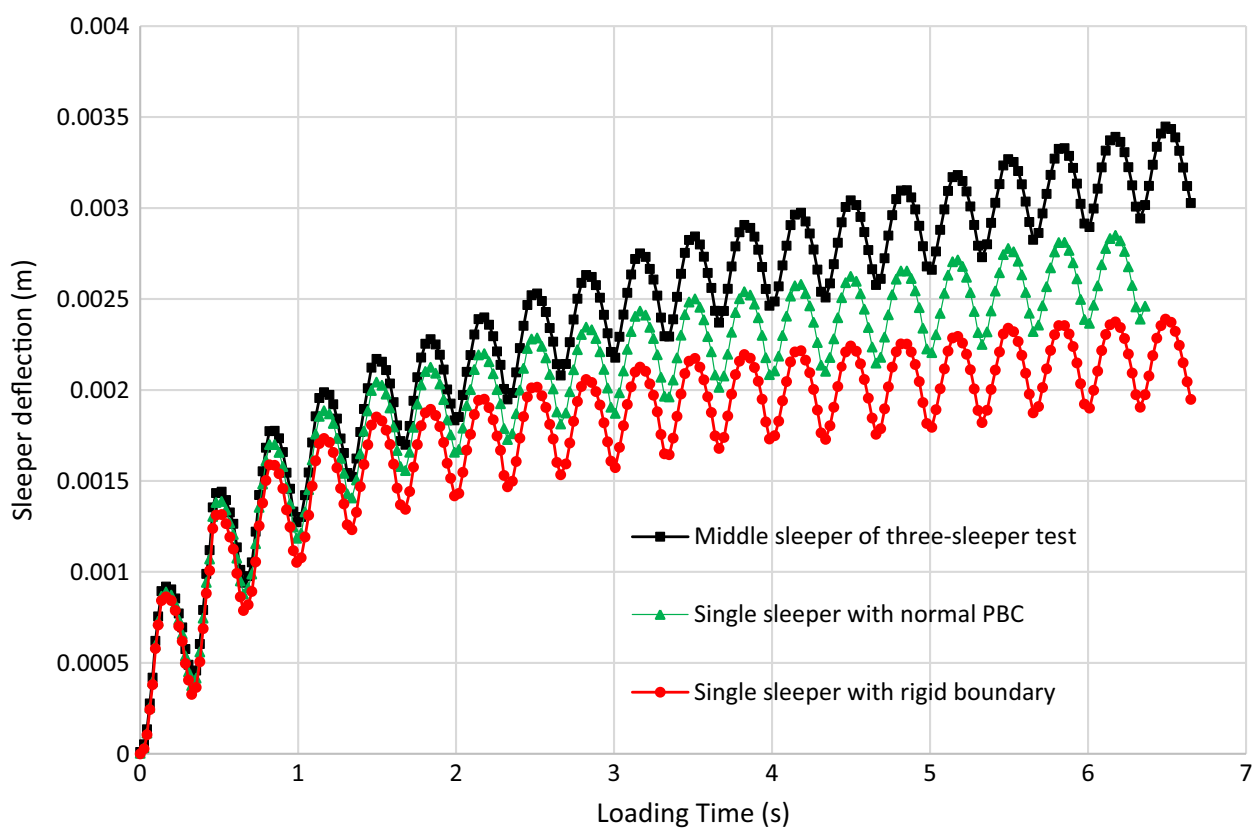




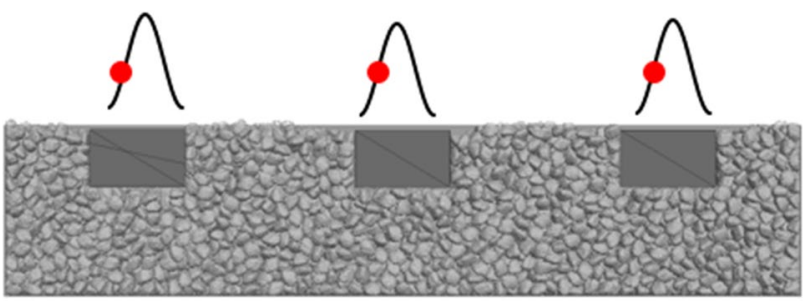

(a)

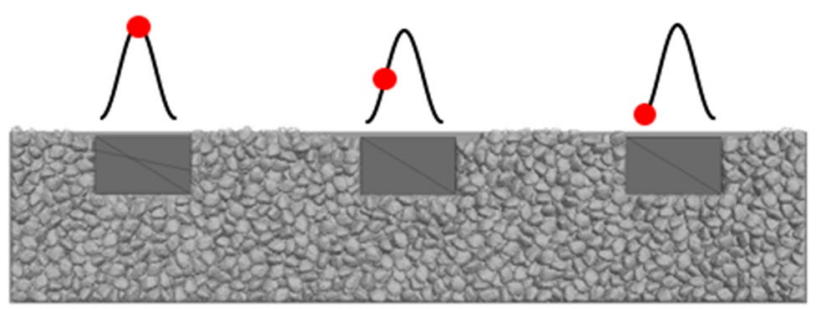

(b)

Fig. 12 The equivalent sleeper loading for (a) normal PBC and (b) time-delayed PBC

have been the leftmost sleeper and rightmost sleeper, each of these would be a quarter of a cycle behind and in front of the middle (current) sleeper respectively. This means that for the average contact force for the left ghost particles is given as (following Eq. (2):

$$
\begin{aligned}
& F_{\text {Ave_left ghost }}=\frac{F_{\text {Ave_max }}+F_{\text {Ave_min }_{\_}}}{2} \\
& +\frac{F_{\text {Ave_max }}-F_{\text {Ave_min }}}{2} * \sin \left(\Phi-\frac{\pi}{2}\right)
\end{aligned}
$$

For the rightmost ghost particles the average magnitude of contact forces is therefore:

$$
\begin{aligned}
F_{\text {Ave_right ghost }}= & \frac{F_{\mathrm{Ave} \_ \text {max }_{-}}+F_{\mathrm{Ave} \_ \text {min }}}{2} \\
& +\frac{F_{\mathrm{Ave} \_ \text {max }_{1}}-F_{\mathrm{Ave} \_ \text {min }}}{2} * \sin \left(\Phi+\frac{\pi}{2}\right)
\end{aligned}
$$

Knowing the average boundary contact forces, it is possible therefore to calculate a current value of contact force for each ghost particle individually:

$f_{\text {left_ghost }}=\frac{F_{\text {Ave_left ghost }}}{F_{\text {Ave_current }}} * f_{\text {detected }}$

$f_{\text {right_ghost }}=\frac{F_{\text {Ave_right ghost }}}{F_{\text {Ave_current }}} * f_{\text {detected }}$

where $f_{\text {detected }}$ represents the current total detected contact force acting on the corresponding boundary particle (e.g. particles $\mathrm{A}$ and $\mathrm{B}$ ) and $f_{\text {left_ghost }}$ and $f_{\text {right_ghost }}$ are the calculated and applied forces on the ghost particles B' and A' at the left and right hand sides of the sample respectively.

By applying $f_{\text {left_ghost }}$ and $f_{\text {right_ghost }}$ to the ghost particles, the modified periodic boundary was called a 'time-delayed periodic boundary'. It is also noted here the velocities and positions are assumed to be those calculated as if there was a normal PBC. This time-delayed PBC was then applied to three different samples (different initial particle locations, as would be the case in a laboratory sample) to verify its effectiveness. ${ }^{*}$ MERGEFORMAT Fig. 15 plots the results
Fig. 13 Load distribution of single sleeper test with fixed boundary at different loading phases in a single loading cycle
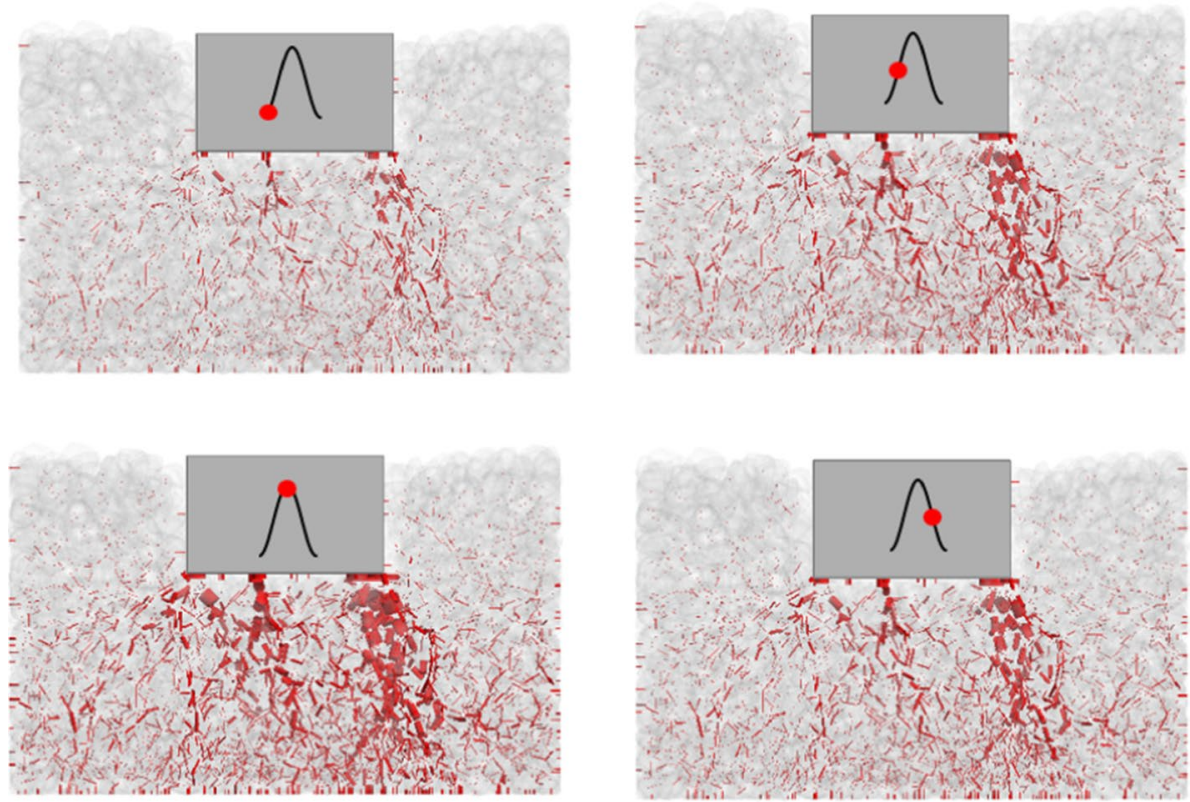


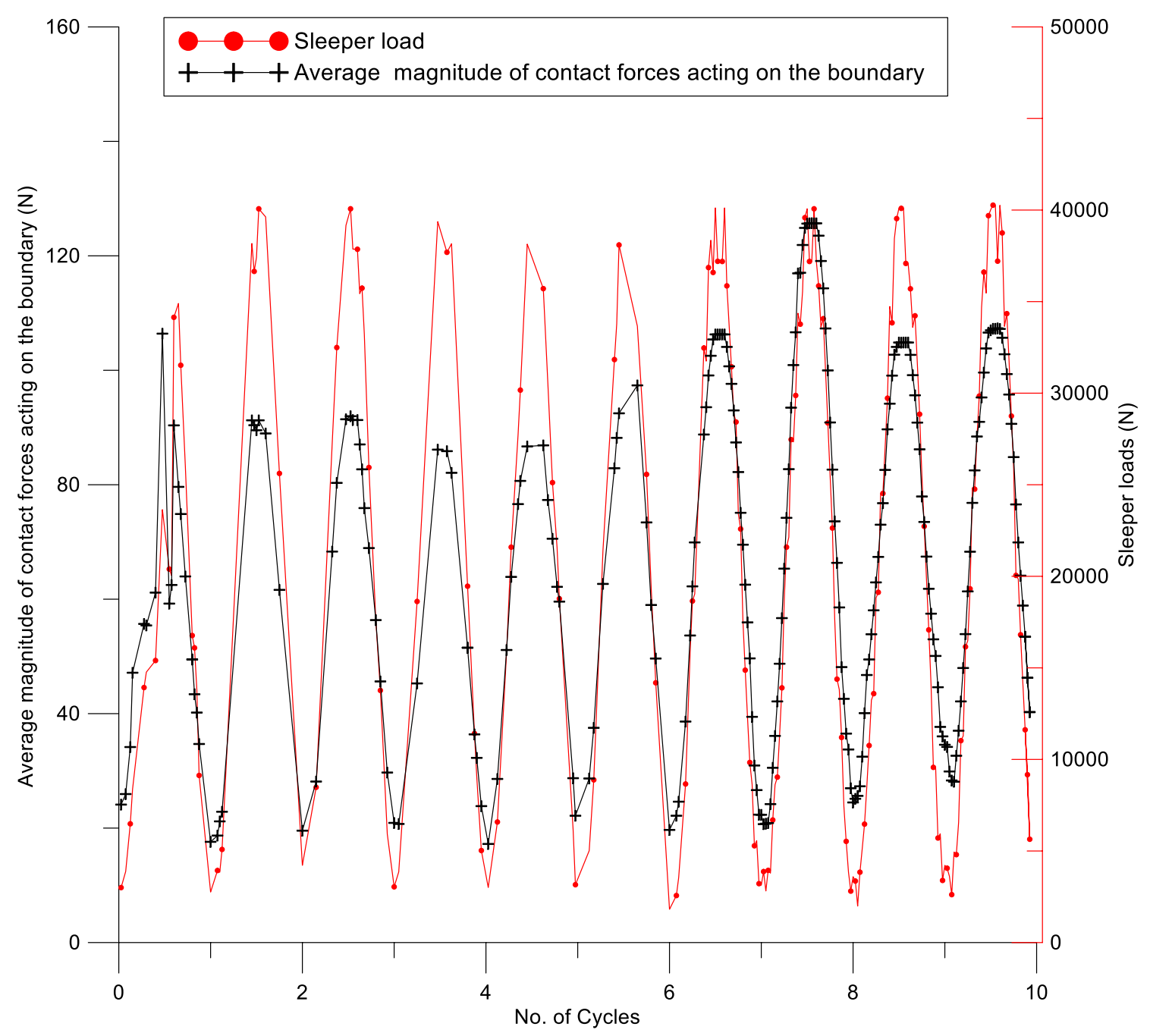

Fig. 14 The average magnitude of contact forces of particles next to the boundary and the sleeper load as a function loading cycle

for all three samples and shows the sleeper deflections as a function of loading time for all four cases: three-sleeper test, fixed boundary, normal PBC and the new time-delayed PBC. It clearly shows the time-delayed periodic boundary presents the closest settlement curve when compared to the threesleeper test. Although there is still a slight gap between the three-sleeper test and the time-delayed boundary, the new time-delayed $\mathrm{PBC}$ predicts the sleeper settlement much better than the normal PBC and the result seems to be repeatable for different initial samples. Therefore, the time-delayed $\mathrm{PBC}$ is more useful when considering an element test with a moving wheel load.

\section{Conclusions}

A novel time-delayed periodic boundary has been proposed for DEM modelling cyclic loading in an element test when the particulate system is subject to travelling loads such as in a railway track. The investigations were based on a box test which is normally used as an element testing model for railway track in DEM studies and also in some laboratory tests. The proposed time-delayed PBC was conducted by predicting the forces acting on ghost particles with the consideration of different loading phases for adjacent sleepers while the normal PBC simply gives the ghost particles the same contact forces as the original particles at 
Fig. 15 The boundary effect of time-delayed periodic boundary for three different samples
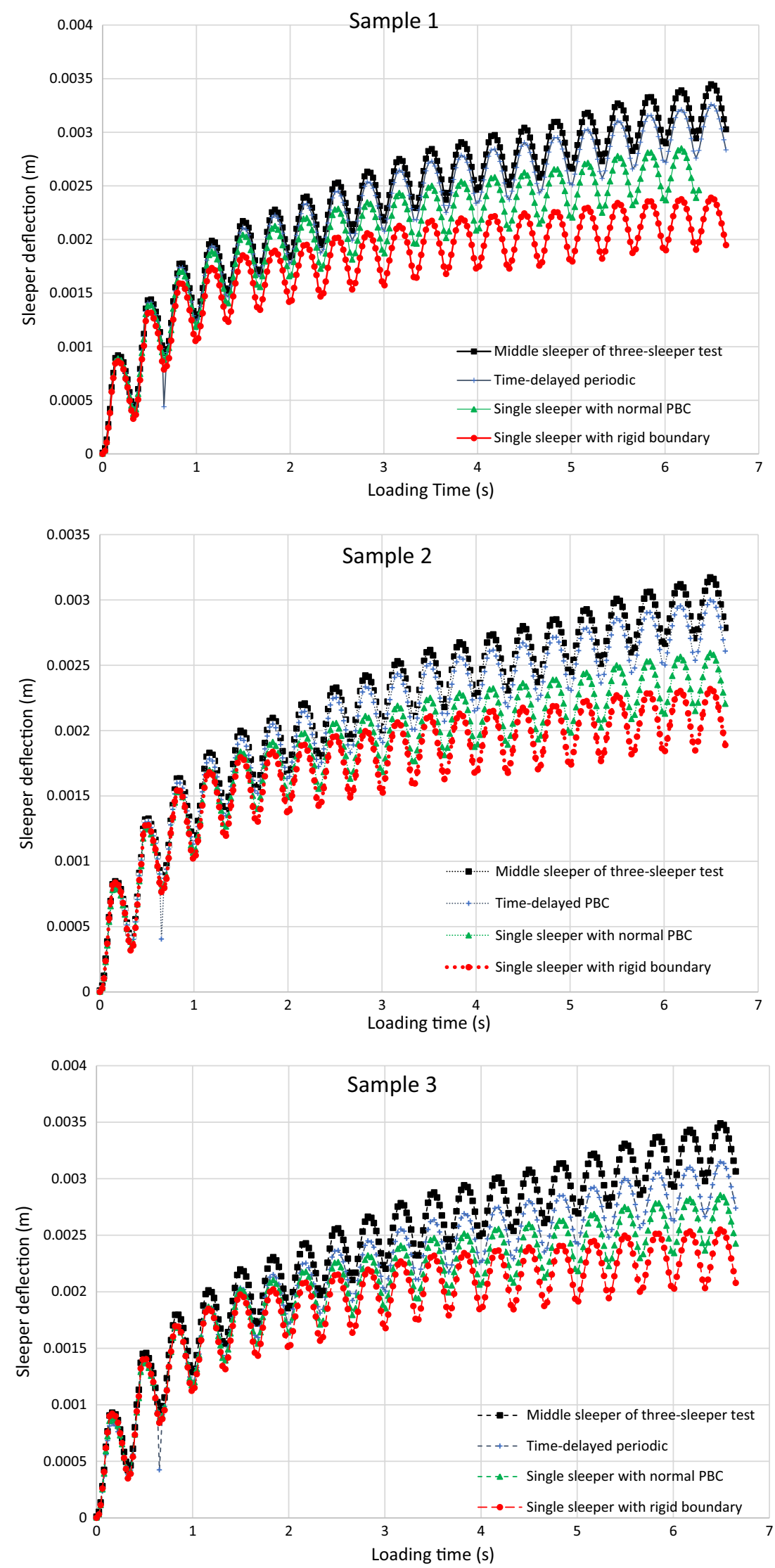
the boundaries. The settlement of the middle sleeper in a three-sleeper test was assumed to give the result of settlement without boundary effects (for that sleeper) and it was compared with the sleeper settlements in a single sleeper test with a fixed boundary, a normal periodic boundary and the newly proposed time-delayed PBC. The comparison shows the time-delayed $\mathrm{PBC}$ increased the accuracy of predicting sleeper settlement compared to the normal PBC or the fixed boundary, which proves that this time-delayed PBC could effectively reduce the boundary effect in DEM modelling of box tests. This provides a new option for researchers to model other similar periodic structures with travelling loads using DEM.

Acknowledgement The authors would like to thank EPSRC Project EP/M025276/1 for funding this work.

\section{Declaration}

Conflict of interest The authors also declare that they have no financial and personal relationships with other people or organizations that can inappropriately influence their work.

Open Access This article is licensed under a Creative Commons Attribution 4.0 International License, which permits use, sharing, adaptation, distribution and reproduction in any medium or format, as long as you give appropriate credit to the original author(s) and the source, provide a link to the Creative Commons licence, and indicate if changes were made. The images or other third party material in this article are included in the article's Creative Commons licence, unless indicated otherwise in a credit line to the material. If material is not included in the article's Creative Commons licence and your intended use is not permitted by statutory regulation or exceeds the permitted use, you will need to obtain permission directly from the copyright holder. To view a copy of this licence, visit http://creativecommons.org/licenses/by/4.0/.

\section{References}

1. Safari Baghsorkhi, M., Laryea, S., McDowell, G., Thom, N.: An investigation of railway sleeper sections and under sleeper pads using a box test apparatus. Proc. Instit. Mech. Eng. Part F J. Rail Rapid Transit. 230(7), 1722-1734 (2016)

2. Li, H., McDowell, G.R.: Discrete element modelling of under sleeper pads using a box test. Granular Matter 20(2), 26 (2018)

3. Danesh, A., Palassi, M., Mirghasemi, A.A.: Effect of sand and clay fouling on the shear strength of railway ballast for different ballast gradations. Granular Matter 20(3), 51 (2018)

4. Tutumluer E, Huang H, Hashash YMA. Discrete element modeling of railroad ballast settlement. In: AREMA Annual Conference (2007)

5. Lobo-Guerrero, S., Vallejo, L.E.: Discrete element method analysis of railtrack ballast degradation during cyclic loading. Granular Matter 8(3-4), 195-204 (2006)

6. Indraratna, B., Lackenby, J., Christie, D.: Effect of confining pressure on the degradation of ballast under cyclic loading. Géotechnique. 55(4), 325-328 (2005)

7. Falagush, O., McDowell, G.R., Yu, H.S., de Bono, J.P.: Discrete element modelling and cavity expansion analysis of cone penetration testing. Granular Matter 17(4), 483-495 (2015)
8. Falagush, O., McDowell, G.R., Sui, Yu.H., de Bono, John P.: Discrete element modelling and cavity expansion analysis of cone penetration testing. Granular Matter 17(4), 483-495 (2015)

9. Falagush, O.: Discrete element modelling of cone penetration testing in granular materials $\mathrm{PhD}$ dissertation. University of Nottingham (2014)

10. Ng, T.T.: Shear strength of assemblies of ellipsoidal particles. Géotechnique. 54(10), 659-669 (2004)

11. Thornton, C.: Numerical simulations of deviatoric shear deformation of granular media. Géotechnique. 50(1), 43-53 (2000)

12. Zhou, Z., Zhu, H., Yu, A., Wright, B., Pinson, D., Zulli, P.: Discrete particle simulation of solid flow in a model blast furnace. ISIJ Int. 45(12), 1828-1837 (2005)

13. Zhou, Z.Y., Zhu, H.P., Wright, B., Yu, A.B., Zulli, P.: Gas-solid flow in an ironmaking blast furnace-II: discrete particle simulation. Powder Technol. 208, 72-85 (2011)

14. Cui, L., O'Sullivan, C., O'Neill, S.: An analysis of the triaxial apparatus using a mixed boundary three-dimensional discrete element model. Géotechnique. 57(10), 831-844 (2007)

15. Grest, G.S., Dünweg, B., Kremer, K.: Vectorized link cell Fortran code for molecular dynamics simulations for a large number of particles. Comput. Phys. 55, 269 (1989)

16. Džiugys, A., Peters, B.: An approach to simulate the motion of spherical and non-spherical fuel particles in combustion chambers. Granular Matter 3(4), 231-266 (2001)

17. Third, J.R., Scott, D.M., Scott, S.A., Müller, C.R.: Effect of periodic boundary conditions on granular motion in horizontal rotating cylinders modelled using the DEM. Granular Matter 13(1), 75-78 (2011)

18. Radjaï, F., Dubois, F.: Discrete-element modeling of granular materials. Wiley-Iste (2011)

19. Brown, S.F., Brodrick, B.V., Thom, N.H., McDowell, G.R.: The Nottingham railway test facility, UK. Proc. Instit. Civ. Eng. Trans. 160(2), 59-65 (2007)

20. Jezequel, L.: Response of periodic systems to a moving load. J. Appl. Mech. 48(3), 613-618 (1981)

21. Sheng, X., Jones, C.J.C., Thompson, D.J.: Responses of infinite periodic structures to moving or stationary harmonic loads. J. Sound Vib. 282(1-2), 125-149 (2005)

22. Ramūnas, V., Gailien, I.: Crushed rock ballast bed in the railway lines of Lithuania: analysis of the situation and arising problems. In: Environmental Engineering, The 9th International Conference (2014)

23. Koivisto, K., Hellberg, J., Forsman, J., Viitala, T.: Finite element modelling of deep stabilization test structures used in attenuating railway induced ground vibration at Koria, Finland. In: Deep Mixing 2009 Okinawa Symposium, Proceedings of The International Symposium on Deep Mixing \& Admixture Stabilisation-DM, vol. 9, pp. 471-476 (2009)

24. Rajesh, S., Choudhary, K., Chandra, S.: A generalized model for geosynthetic reinforced railway tracks resting on soft clays. Int. J. Numer. Anal. Meth. Geomech. 39(3), 310-326 (2015)

25. Chen, C., McDowell, G.R., Thom, N.H.: Investigating geogridreinforced ballast: Experimental pull-out tests and discrete element modelling. Soils Found. 54(1), 1-11 (2014)

26. Suhr, B., Marschnig, S., Six, K.: Comparison of two different types of railway ballast in compression and direct shear tests: experimental results and DEM model validation. Granular Matter 20(4), 70 (2018)

27. Horvát, F., Fischer, S., Major, Z.: Evaluation of railway track geometry stabilisation effect of geogrid layers under ballast on the basis of laboratory multi-level shear box tests. Acta Technica Jaurinensis. 6(2), 21-44 (2013) 
28. Lu, M., McDowell, G.R.: The importance of modelling ballast particle shape in the discrete element method. Granular Matter 9(1-2), 69-80 (2006)

29. Rujikiatkamjorn, C., Indraratna, B., Ngo, N.T., Coop, M.: A laboratory study of railway ballast behaviour under various fouling degree. In: Geosynthetics Asia, 5th Asian Regional Conference on Geosynthetics (2012)

30. Fischer S, Németh A. Special laboratory testing method for evaluation particle breakage of railway ballast material. Наука и прогресс транспорта. Вестник Днепропетровского национального университета железнодорожного транспорта 2 (74) (2018)

31. Kennedy J.: A full-scale laboratory investigation into railway track substructure performance and ballast reinforcement. $\mathrm{PhD}$ diss., Heriot-Watt University (2011)

32. Huang, H., Tutumluer, E.: Discrete element modeling for fouled railroad ballast. Constr. Build. Mater. 25(8), 3306-3312 (2011)

33. McDowell, G.R., Lim, W.L., Collop, A.C.: Comparison of ballast index tests for railway trackbeds. In: Proceedings of the Institution of Civil Engineers-Geotechnical Engineering, vol. 157(3), pp. 151-11 (2004)

34. Mead, D.J.: Vibration response and wave propagation in periodic structures. J. Eng. Ind. 93(3), 783 (1971)

35. Krzyzynski, T., Popp, K.: On the travelling wave approach for discrete-continuous structures under moving loads. Zeitschrift für angewandte Mathematik und Mechanik, vol. 76, pp. 149-152 (1996)

36. Krzyzynski, T.: On dynamics of a railway track modelled as a two dimensional periodic structure. Int. J. Heavy Vehicle 6, 330-334 (1999)

37. Chebli, H., Othman, R., Clouteau, D.: Response of periodic structures due to moving loads. Comptes Rendus Mécanique. 334(6), 347-352 (2006)
38. Kumar, N., Suhr, B., Marschnig, S., Dietmaier, P., Marte, C., Six, K.: Micro-mechanical investigation of railway ballast behavior under cyclic loading in a box test using DEM: effects of elastic layers and ballast types. Granular Matter 21(4), 106 (2019)

39. Baghsorkhi, M.S., Laryea, S., Ferellec, J.F.: Sleeper geometry investigations using discrete element modelling and the box test apparatus. In: Proceedings of the Second International Conference on Railway Technology: Reseacgm Development and Maintenance. vol. 8 (2014)

40. Lobo-Guerrero, S., Vallejo, L.E.: Discrete element method evaluation of granular crushing under direct shear test conditions. J. Geotech. Geoenviron. Eng. 131(10), 1295-1300 (2005)

41. Itasca. PFC3D v5.0-user manual. Minneapolis; (2015)

42. Li, H., McDowell, G., Lowndes, I.: Discrete-element modelling of rock communition in a cone crusher using a bonded particle model. Géotech. Lett. 4(2), 79-82 (2014)

43. Li, H., McDowell, G., Lowndes, I.: Discrete element modelling of a rock cone crusher. Powder Technol. 263, 151-158 (2014)

44. Taghavi, R.: Automatic clump generation based on mid- surface. In: Proceedings, 2nd international FLAC/DEM symposium. Melbourne, pp. 791-797 (2011)

45. Burnham, NR., Network Rail and IEC 61850, A user's perspective of the Standard. In: Conference on Developments in Power Systems (2012)

Publisher's Note Springer Nature remains neutral with regard to jurisdictional claims in published maps and institutional affiliations. 